\title{
A Simple Thermal Treatment Synthesis and Characterization of Ni-Zn Ferrite (Ni0.5Zn0.5Fe2O4) Nanocrystals
}

\author{
Lin Leng $\mathrm{P}^{1}$, Saion $\mathrm{E}^{1},{ }^{*}$., Goodarz Naseri $\mathrm{M}^{2}{ }^{2}$, , Mehdipour L.A ${ }^{1}$, Shaari A. $\mathrm{H}^{1}$, \\ Ahmad Kamaruddin $\mathbf{M}^{1}$. \\ 1Department of Physics, Universiti Putra Malaysia, 43400 Serdang, Selangor, Malaysia \\ 2Department of Physics, Faculty of Science, Malayer University, Malayer, Iran
}

\begin{abstract}
Cubic structured nickel-zinc ferrite nanoparticles $\left(\mathrm{Ni}_{0.5} \mathrm{Zn}_{0.5} \mathrm{Fe}_{2} \mathrm{O}_{4}\right)$ have been synthesized by thermal treatment method. This simple procedure employed an aqueous solution containing only metal nitrates as precursors, polyvinyl pyrrolidone as a capping agent, and deionized water as a solvent. The solution was thoroughly stirred for 2 hour, dried at $353 \mathrm{~K}$ for 3 hour, the dried material crushed into powder and calcined the powder at $873 \mathrm{~K}$ to remove organic substances and crystallize the particles. The microstructure properties of the prepared ferrite nanoparticles were measured using FTIR, XRD, TEM, and EDX and the magnetic properties were determined using VSM and EPR. The average particle size increased from 7 to $22 \mathrm{~nm}$ with the increase of calcination temperature from 723 to $873 \mathrm{~K}$. The saturation magnetization, coercivity field, and $\mathrm{g}$ factor increased respectively from $24 \mathrm{emu} / \mathrm{g}, 11 \mathrm{G}$, and $2.0673 \mathrm{at} 723 \mathrm{~K}$ to $38 \mathrm{emu} / \mathrm{g}, 60 \mathrm{G}$, and $2.1227 \mathrm{at} 873 \mathrm{~K}$. This method offers simplicity, a low cost, and an environmentally friendly operation since it produces no byproduct effluents.
\end{abstract}

Keywords: Thermal treatment; nickel-zinc ferrite; nanoparticles; structural and magnetic properties

\section{Introduction}

The last two decades have seen tremendous progress in the synthesis of nanomaterials to search for nanoparticles with improved physical and chemical properties by enhancement of the surface and quantum confinement effects[1,2].In particular, the Ni-Zn ferrite nanocrystals which are regarded as an important soft ferrite have been extensively studied due to their super-paramagnetic properties suitable for high-frequency applications such as rod antennas and cores of inductors and transformers [3, 4]. It has been shown that the properties of ferrite nanoparticles are generally enhanced compared to their bulk counterparts $[5,6]$.The metal ferrites have a spinel structural formula $\mathrm{AB}_{2} \mathrm{O}_{4}$ where the divalent cations has high degree affinity for tetrahedral A sites and the trivalent cation has high degree affinity for octahedral B sites. However, for Ni-Zn ferrite nanoparticles, the octahedral sites preference for $\mathrm{Ni}$ and the tetrahedral preference for $\mathrm{Zn}$ [3], given by the formula $\left(\mathrm{Zn}^{2+}{ }_{\mathrm{x}} \mathrm{Fe}^{3+}{ }_{1-\mathrm{x}}\right)\left(\mathrm{Ni}_{1-\mathrm{x}} \mathrm{Fe}^{3+}{ }_{1+\mathrm{x}}\right) \mathrm{O}_{4}(0 \leq \mathrm{x} \leq 1)$, where the first and second brackets indicate occupancy of the $\mathrm{A}$ and $\mathrm{B}$ sub-lattices respectively. The super-paramagnetic properties of the Ni-Zn ferrite nanoparticles are sensitive to the particle size, shape, and size distribution, which can be controlled in the fabrication process. Considerable interest in diverse methods for the synthesis of $\mathrm{Ni}-\mathrm{Zn}$ ferrite nanoparticles has been devoted to explore better materials with controllable size, shape, and stability for a variety of applications. Various fabrication methods have been proposed such thermal combustion method [7], as sol-gel methods [8], citrate route [9], co-precipitation method [5,6], thermal plasma synthesis [10], reverse micelle [11], hydrothermal [12, 13], micro-emulsion [14] and sonochemical reaction [15]. Various precipitants have been used to reduce the metal oxides such as ammonia in the hydrothermal, reverse micelle and co-precipitation method and citrate acid in citrate route and sol-gel method. Most of these methods can produce nanoparticles of required particle size, shape,size distribution, andchemical composition. However,they might also encompass adverse cost such as complicated procedure, high reaction temperature, long reaction time, and their by products could contribute to the environmental degradation because the use of precipitants. In the present study, Ni- $\mathrm{Zn}$ ferrite nanoparticles $\mathrm{Ni}_{0.5} \mathrm{Zn}_{0.5} \mathrm{Fe}_{2} \mathrm{O}_{4}$ were synthesized using a simple thermal treatment method from an aqueous solution containing only metal nitrates as precursors, polyvinyl pyrrolidone (PVP) as a capping agent and deionized water as solvent. No other chemicals were added into the solution, thus this method offers several advantages over the conventional methods in terms of simplicity, low reaction temperatures, a low cost, and an environmentally friendly operation since it produces no by-product effluents [16-19].

\section{Experimental Section}

2.1 Chemicals:Iron (III) nitrate, $\mathrm{Fe}\left(\mathrm{NO}_{3}\right)_{3} \cdot \underline{9 \mathrm{H}_{2}} \underline{\mathrm{O}}$, nickel(II) nitrate, $\mathrm{Ni}\left(\mathrm{NO}_{3}\right)_{2} \cdot 6 \mathrm{H}_{2} \mathrm{O}$, and zinc nitrate, $\mathrm{Zn}\left(\mathrm{NO}_{3}\right)_{2} \cdot 6 \mathrm{H}_{2} \mathrm{O}$ were purchased from Acros Organics and PVP (MW=29000) was supplied by Sigma Aldrich. All the chemical reagents were of research grade exceeding $99 \%$ and used as received and without further purification. 


\subsection{Sample preparation}

$3 \mathrm{~g}$ of PVP was dissolved in $100 \mathrm{ml}$ of deionized water at $343 \mathrm{~K}$ before mixing $0.2 \mathrm{mmol}$ of iron (III) nitrate, $0.05 \mathrm{mmol}$ of nickel (II) nitrate and $0.05 \mathrm{mmol}$ zinc nitrate into the polymer solution and stirred constantly for $2 \mathrm{~h}$ until brown solution was obtained. The mixed solution was poured into a glass Petri dish and heated at $353 \mathrm{~K}$ in an oven for 24 hours to evaporate most of the water. No precipitation was observed in the solution before drying in the oven. The dried brown solid material was crushed in a mortar to form powder before calcinations the samples in alumina boats at different temperatures of $723,773,823$ and $873 \mathrm{~K}$ for $3 \mathrm{~h}$ each to decompose the organic substances and crystallize the nanoparticles.

\subsection{Sample characterization}

The characterizations of $\mathrm{Ni}_{0.5} \mathrm{Zn}_{0.5} \mathrm{Fe}_{2} \mathrm{O}_{4}$ nanoparticles were conducted using several techniques to explore the parameters of interest related to structural and magnetic properties. The spinel phase structure and particle size were characterized by X-ray powder diffraction (XRD)using a Shimadzu diffract meter model XRD 6000 employing $\mathrm{Cu} \mathrm{K}_{\alpha} \mathrm{X}$-ray $(0.154 \mathrm{~nm})$ to generate diffraction patterns from powder crystalline samples in $2 \theta$ range of $10-70^{\circ}$. The particle morphology and size were determined at room temperature by transmission electron micrograph (TEM) (JEOL 2010 UHR version microscopy) at an accelerating voltage of 200kV.To confirm the removal of organic substances during calcination, the infrared spectra in the range $280-4000 \mathrm{~cm}^{-1}$ were recorded using FTIR spectrometer (Perkin Elmer model 1650). The saturation magnetization and coercivity values were determined at room temperature using a vibration sample magnetometer (VSM) (Lake Shore 4700) with a maximum magnetic field of $15 \mathrm{kOe}$. The peak-to-peak line width $\left(\square \mathrm{H}_{\mathrm{p}}\right.$ ), resonant magnetic field $(\mathrm{H})$,and g-factor were recorded from JEOL JES-FA200 electron paramagnetic resonance (EPR) spectrometer (JEOL, Tokyo, Japan) at room temperature.

\subsection{Structural analysis}

\section{Results And Discussion}

Fig. 1 shows the schematic diagram of proposed interactions between the metal ions and the PVP capping agent. Metallic ions are bound by the strong ionic bonds through steric and electrostatic stabilization of the amide groups of the polymeric chain. This uniform immobilization of metallic ions in the cavities of the polymer chains and methylene groups in favour of the formation of uniformly distributed metallic ions for the construction of metallic oxides after calcination process $[16,18]$.

Fig. 2 shows EDX pattern of the sample calcined at $873 \mathrm{~K}$, which shows the Ni, Zn, Fe and O peaks appear along with the $\mathrm{C}$ substrate peak. No contaminating elements from reagents, such as hydrogen or nitrogen were detected. The average composition of $\mathrm{Ni}_{0.5} \mathrm{Zn}_{0.5} \mathrm{Fe}_{2} \mathrm{O}_{4}$ nanoparticles was estimated from the EDX spectra. Fig. 3 shows the FTIR spectra of $\mathrm{Ni}_{0.5} \mathrm{Zn}_{0.5} \mathrm{Fe}_{2} \mathrm{O}_{4}$ nanoparticles recorded in the range of $280 \mathrm{~cm}^{-1}$ to $4000 \mathrm{~cm}^{-1}$. The FTIR spectra give information about the chemical and molecular structure changes in the synthesized ferrites after calcination at temperatures of $723,773,823$ and $873 \mathrm{~K}$. The absorption peaks above $1000 \mathrm{~cm}^{-1}$ were attributed to covalent bonds of PVP. The bending mode at $1644 \mathrm{~cm}^{-1}$ was associated with $\mathrm{C}=\mathrm{O}$ stretching vibration and that at $3490-3505 \mathrm{~cm}^{-1}$ was associated with $\mathrm{O}-\mathrm{H}$ stretching vibration. The absence of peaks above $1000 \mathrm{~cm}^{-1}$ confirmed the absence of the $\mathrm{C}=\mathrm{O}$ and $\mathrm{O}-\mathrm{H}$ stretching modes of organic substances at calcination temperature $873 \mathrm{~K}$. At this temperature we observed only the absorption peaks of 360 and $556 \mathrm{~cm}^{-1}$, which were assigned to the $\mathrm{Zn}-\mathrm{O}, \mathrm{Ni}-\mathrm{O}$, and $\mathrm{Fe}-\mathrm{O}$ stretching bands. This indicates that at calcination temperature $873 \mathrm{~K}$ the prepared spinel $\mathrm{Ni}_{0.5} \mathrm{Zn}_{0.5} \mathrm{Fe}_{2} \mathrm{O}_{4}$ nanoparticles were in pure state. Therefore, using FTIR analysis we can ensure the removal of the unwanted organic substances from the prepared $\mathrm{Ni}_{0.5} \mathrm{Zn}_{0.5} \mathrm{Fe}_{2} \mathrm{O}_{4}$ nanoparticles.

Fig. 4 shows the XRD diffraction patterns of the $\mathrm{Ni}_{0.5} \mathrm{Zn}_{0.5} \mathrm{Fe}_{2} \mathrm{O}_{4}$ nanoparticles at $353 \mathrm{~K}$ and at different calcination temperatures of $673,723,823$ and $873 \mathrm{~K}$. The diffraction patterns show the reflection planes (111), (220), (311), (400), (422), (333) and (440) which are consistent with the standard powder diffraction reported from XRD library code (00-052-0278) for the $\mathrm{Ni}_{0.5} \mathrm{Zn}_{0.5} \mathrm{Fe}_{2} \mathrm{O}_{4}$ and no other metal oxides could be identified. All samples were formed in single phase with a face centered cubic structure. The crystallite size was analyzed from the XRD plane (311) by the Scherrer formula: $D=0.9 \lambda / \beta \cos \theta$, where $D$ is the average particle size in $\mathrm{nm}, \beta$ is the FWHM of the intensity measured in radians, $\lambda$ is the X-ray wavelength and $\theta$ is the Bragg angle. The average particle size increased from $11 \mathrm{~nm}$ at $723 \mathrm{~K}$ to $20 \mathrm{~nm}$ at $873 \mathrm{~K}$, as listed in Table 1 .

The TEM images in Fig. 5 show the size, shape and size distribution of the $\mathrm{Ni}_{0.5} \mathrm{Zn}_{0.5} \mathrm{Fe}_{2} \mathrm{O}_{4}$ nanoparticlesat different temperatures from 723 to $873 \mathrm{~K}$. The particle size increased when the calcination temperature increased from $7 \mathrm{~nm}$ at $673 \mathrm{~K}$ to $22 \mathrm{~nm}$ at $873 \mathrm{~K}$ (Table 1). The morphology and the particle size were uniform and the particle size increased with the increase of calcination temperature due to surface particles melted and fused with the neighbouring particles [19-21]. There is a good agreement of the average particles size between XRD and TEM at higher calcination temperatures. The average diameters of $\mathrm{Ni}_{0.5} \mathrm{Zni}_{0.5} \mathrm{Fe}_{2} \mathrm{O}_{4}$ nanoparticles in the range 5-8 $\mathrm{nm}$ have been reported and the particles were synthesized using the forced hydrolysis in polyol from the corresponding iron, nickel and zinc acetate[20].Using the combustion 
method, the $\mathrm{Ni}_{0.5} \mathrm{Zni}_{0.5} \mathrm{Fe}_{2} \mathrm{O}_{4}$ nanoparticles with the grain sizes between 10 and $20 \mathrm{~nm}$ were obtained[21]. Also the $\mathrm{Ni}_{0.5} \mathrm{Zni}_{0.5} \mathrm{Fe}_{2} \mathrm{O}_{4}$ sizes ranging from 20.8 to $53.3 \mathrm{~nm}$ have been reported using the preparation method of chemical co-precipitation process with metal nitrate and acetate as precursors [22].

\subsection{Magnetic properties}

Fig. 6 shows the curves of magnetization measured at room temperature and the values of the saturation magnetization and coercivity are depicted in Table 1. The saturation magnetization increased from 24 to $38 \mathrm{emu} / \mathrm{g}$ by increasing the calcination temperature. This may be attributed to the surface effects which composed of some distorted and slanted spins that repel the core spins to align the field direction. The magnetization curves demonstrate a typical superparamagnetic behavior. The saturation magnetization were smaller than for the bulk Ni-Zn ferrites of about $70 \mathrm{emu} / \mathrm{g}$. The coercivity value increased from 11 to $60 \mathrm{G}$ when increased the calcination temperatures from 723 to $873 \mathrm{~K}$. The coercivity values were larger than about $5 \mathrm{G}$ compare with the coercivity value of the bulk Ni-Zn ferrites at room temperature. The coercivity is in direct proportional to the volume of single domain grains that increased from 7 to $22 \mathrm{~nm}$ at the calcination temperatures from 723 to $873 \mathrm{~K}$. Fig. 7 shows the EPR spectra of the samples calcined at (a) 723, (b) 773, (c) 823 and (d) $873 \mathrm{~K}$. The peak-to-peak line width $\left(\Delta \mathrm{H}_{\mathrm{pp}}\right)$, resonant magnetic field $(\mathrm{H})$,and g-factor are three parameters that characterized the magnetic properties. The g-factor can be calculated according to the equation: $\mathrm{g}=\mathrm{h} v / \beta \mathrm{H}$ where $\mathrm{h}$ is Planck's constant, $v$ is the microwave frequency, $\beta$ is the Bohr magneton $\left(9.274 \times 10^{-21} \mathrm{erg}\right.$ $\mathrm{G}^{-1}$ ), and $\mathrm{H}$ is resonant magnetic field. The values of $\mathrm{g}$-factor increased from 2.0673 to 2.1227 correspond to the decrease of the resonance magnetic field from 3177 to $3094 \mathrm{G}$ with the increase of calcination temperature from $723 \mathrm{~K}$ to $873 \mathrm{~K}$.

\section{Conclusions}

The $\mathrm{Ni}_{0.5} \mathrm{Zn}_{0.5} \mathrm{Fe}_{2} \mathrm{O}_{4}$ nanocrystals with grain size in the range of 7 to $22 \mathrm{~nm}$ were successfully synthesized by a simple thermal treatment method utilizing only metal nitrates, PVP, and deionized water in absence of capping agent. The average particle size increased with the increase of calcination temperatures from 723 and $873 \mathrm{~K}$ as confirmed by the XRD and TEM analyses. The FTIR analysis established the presence of pure $\mathrm{Ni}_{0.5} \mathrm{Zn}_{0.5} \mathrm{Fe}_{2} \mathrm{O}_{4}$ nanoparticles and the removal of organic substances completely at $873 \mathrm{~K}$. The magnetic measurements show that there were an increase of the saturation magnetization from 24 to $38 \mathrm{emu} / \mathrm{g}$,the coercivity value from 11 to $60 \mathrm{G}$, the g-factor from 2.0673 to2.1227, and the resonance magnetic field from 3177 to $3094 \mathrm{G}$ with the increase of the particles size from 7 to $22 \mathrm{~nm}$. This method is simple, low cost, low reaction temperatures and no by product, can be used to fabricate pure $\mathrm{Ni}_{0.5} \mathrm{Zn}_{0.5} \mathrm{Fe}_{2} \mathrm{O}_{4}$ nanocrystals.

\section{Acknowledgments}

This work was supported by the Ministry of Higher Education of Malaysia under the FRGS grant and Universiti Putra Malaysia under the RUGS grant.

\section{References}

[1] S. Bellucci, J. Phys.Condens. Matter 20 (2008) 470301

[2] M. Baghbanzadeh, L. Carbone, P.D. Cozzoli, C.O.Kappe, Chem. Int. Ed. 50 (2011) 11312.

[3] G.R. Amiri, M.H. Yousefi, M.R. Abolhassani, S. Manouchehri, M.H.Keshavarz, S. Fatahian, J. Magn. Magn.Mater.323 (2011)730.

[4] M. Mohapatra,S. Anand,Inter. J. Eng. Sci. Tech. 2(2010) 127.

[5] E. Manova, D. Paneva, B. Kunev, E. Rivière, C. Estournès, I Mitov,J.Phys, Conf. Series217 (2010)012102.

[6] K. Velmurugan,V.S.K. Venkatachalapathy, S. Sendhilnathan, Mater.Res. 13 (2010) 299

[7]. T.B. Naughton, P. Majewski, D.R. Clarke,J. Am. Ceram. Soc. 90 (2007) 3547.

[8]. E.E. Sileo, R. Rotelo, S.E. Jacobo, Physica B 320 (2002) 257.

[9] R.K. Singh, C. Upadhyay, S.Layek, A. Yadav, Inter. J. Eng. Sci. Tech. 2 (2010) 104.

[10] M.Shigeta, A.B. Murphy, 2011. J. Phys. D: Appl. Phys. 44 (2011) 174025

[11] S.A. Morrison, C.L. Cahill, E.E. Carpenter, S. Calvin, R.Swaminathan, M.E. McHenry, V.G. Harris, J. Appl. Phys. 95 (2004) 6392.

[12] S. Thakur, S.C. Katyal, A. Gupta, V.R. Reddy, S.K. Sharma, M. Knobel, M. Singh, J. Phys. Chem. C 113 (2009) 20785.

[13] P.E. Meskin, V.K. Ivanov, A.E. Barantchikov, B.R. Churagulov, Y.D. Tretyakov, Ultra. Sonochem. 13 (2006) 47.

[14] D Mathew, R Juang, Chem. Eng. J.129(2007) 51.

[15] M.Sivakumar, T.Takami, H. Ikuta, A.Towata, K.Yasui, T.Tuziuti, T.Kozuka, D. Bhattacharya, Y.Lida, J. Phys. Chem. B, 2006, 110 (2006) 15234.

[16] M.G. Naseri, E.B. Saion, M.Hashim, A.H.Shaari, H.A.Ahangar, Sol. Stat. Com. 151 (2011) 1031

[17] M.G.Naseri, E.B.Saion, H.A. Ahangar, M.Hashim, A.H.Shaari, J. Magn. Magn.Mater.323 (2011) 1745.

[18] M.G. Naseri, E.B. Saion, H.A. Ahangar, M. Hashim, A.H.Shaari, Pow. Techn.212 (2011) 80.

[19] M.G. Naseri, E.B. Saion, H.A. Ahangar, A.H. Shaari, M.Hashim, J. Nanomater.2010 (2010) 907686. 


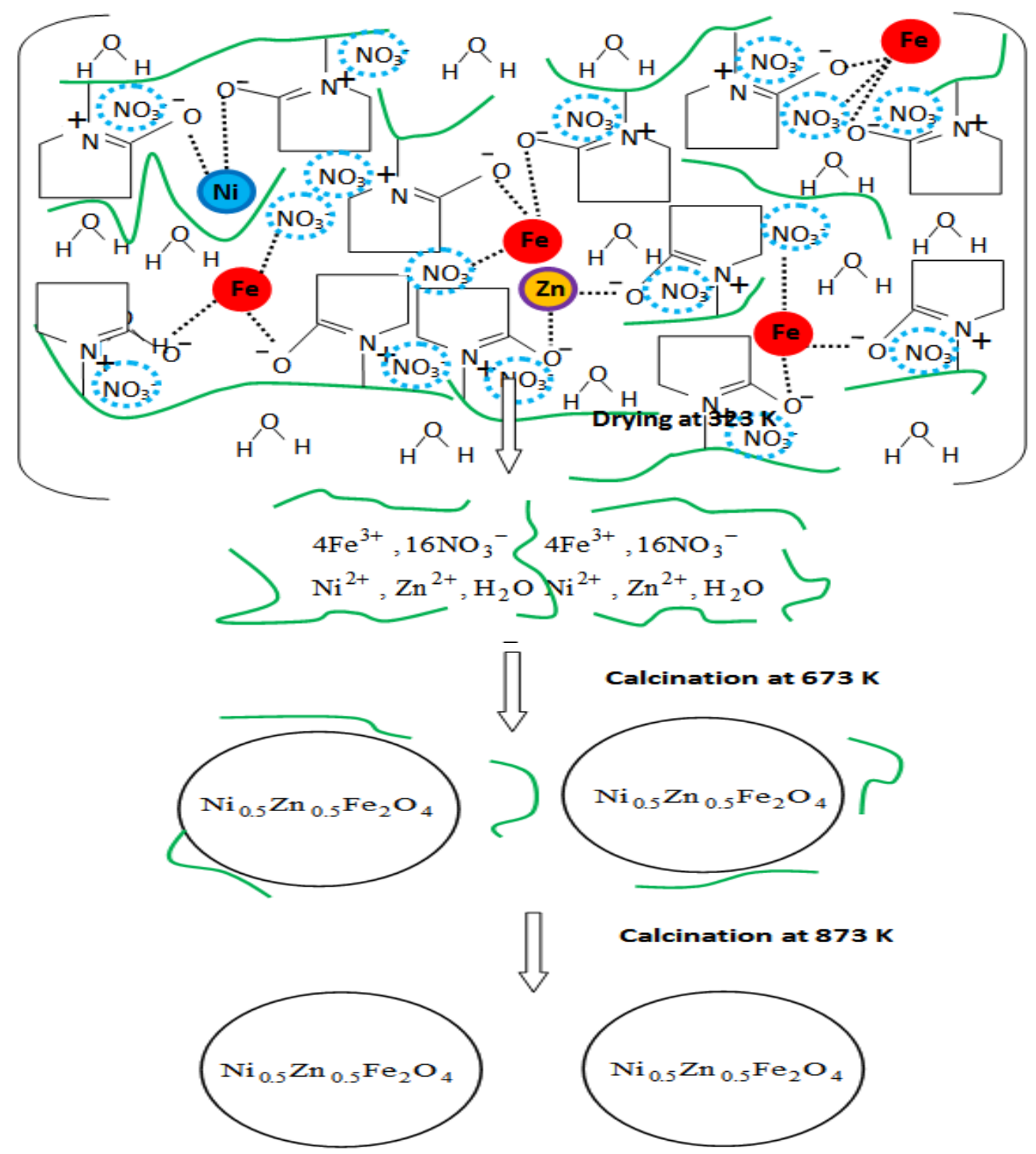

Fig. 1: Schematic diagram of proposed interactions between the metal ions and PVP.

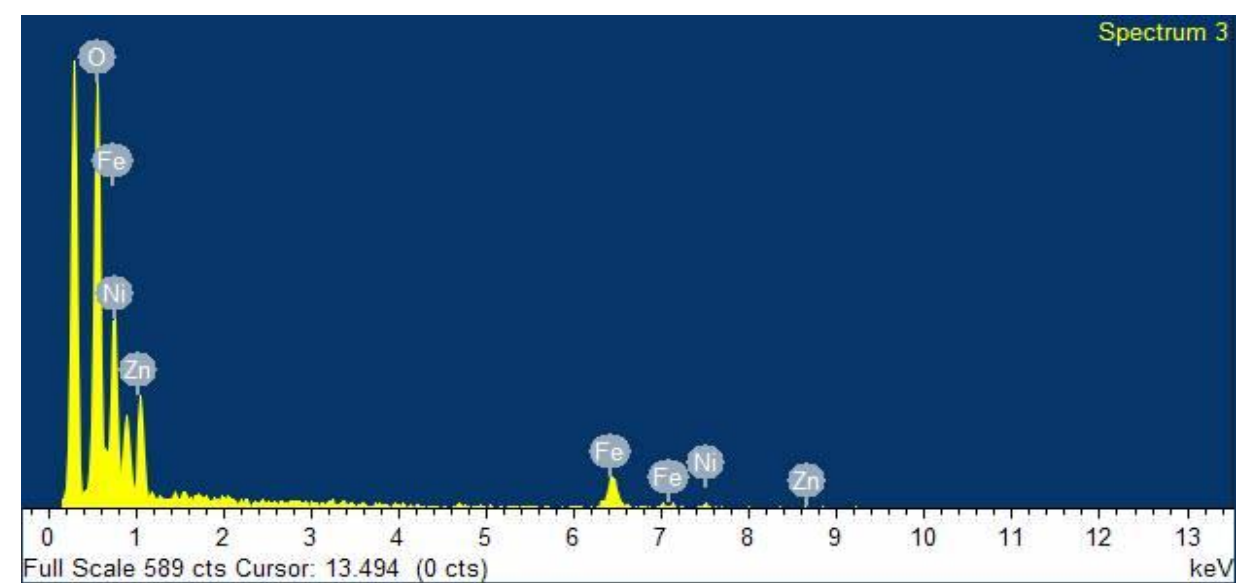

Fig. 2: EDX pattern of the sample calcined at $873 \mathrm{~K}$, which shows the $\mathrm{Ni}, \mathrm{Zn}, \mathrm{Fe}$ and $\mathrm{O}$ peaks appear along with the $\mathrm{C}$ substrate peak 


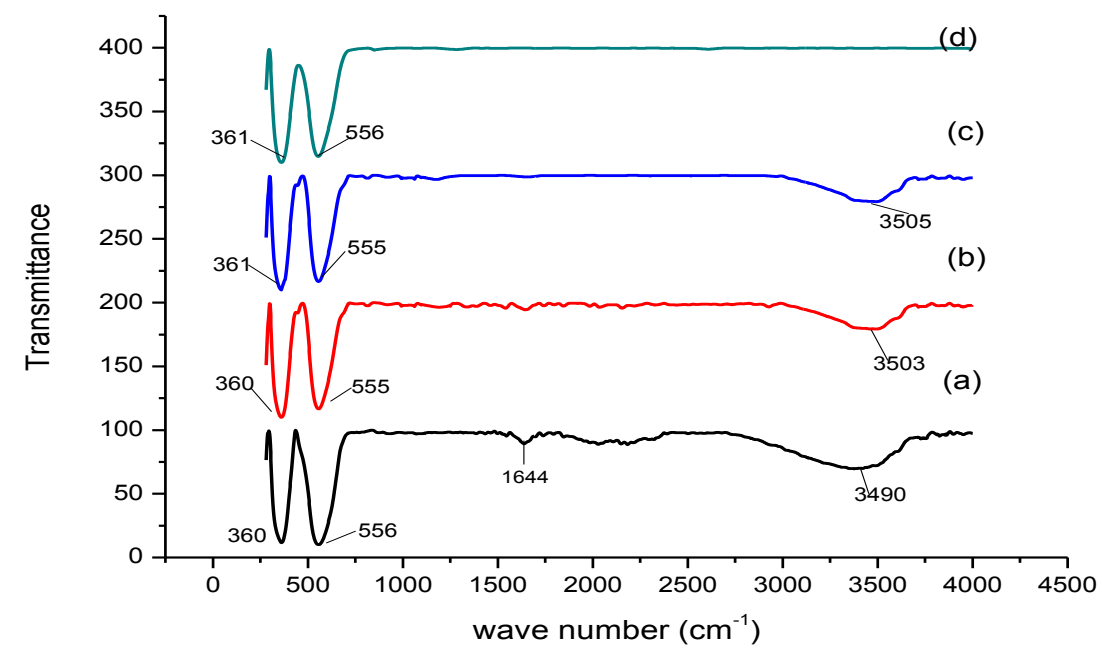

Fig.3: FTIR spectra of $\mathrm{Ni}_{0.5} \mathrm{Zn}_{0.5} \mathrm{Fe}_{2} \mathrm{O}_{4}$ nanoparticles calcined at (a) 723, (b) 773, (c) 823 and (d) $873 \mathrm{~K}$.

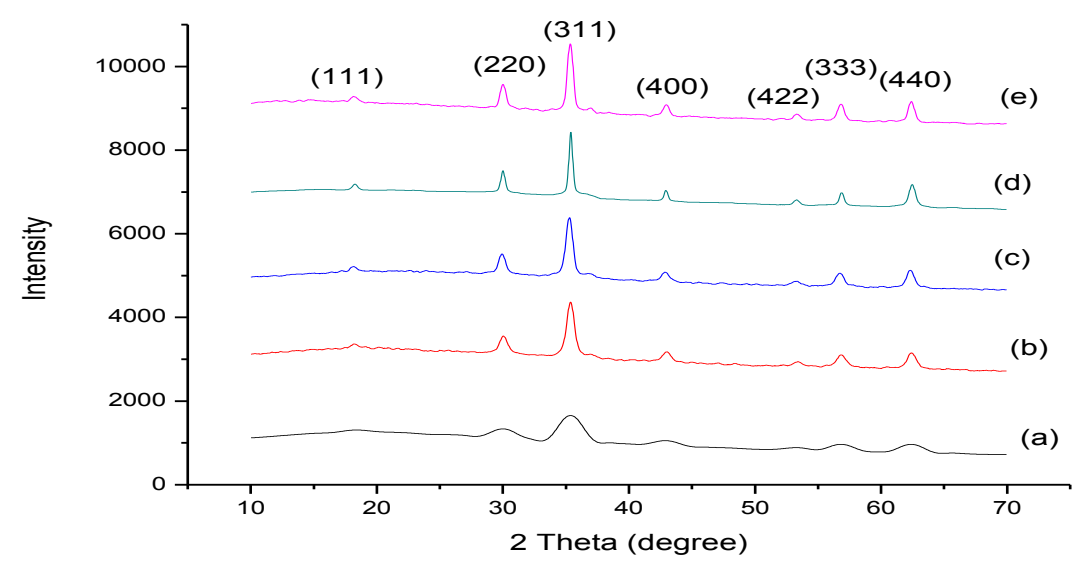

Fig.4: XRD pattern of $\mathrm{Ni}_{0.5} \mathrm{Zn}_{0.5} \mathrm{Fe}_{2} \mathrm{O}_{4}$ nanoparticles (a) dried at $353 \mathrm{~K}$ and calcined at (b) 723, (c) 773, (d) 823 and (e) $873 \mathrm{~K}$.



(a) 




(b)

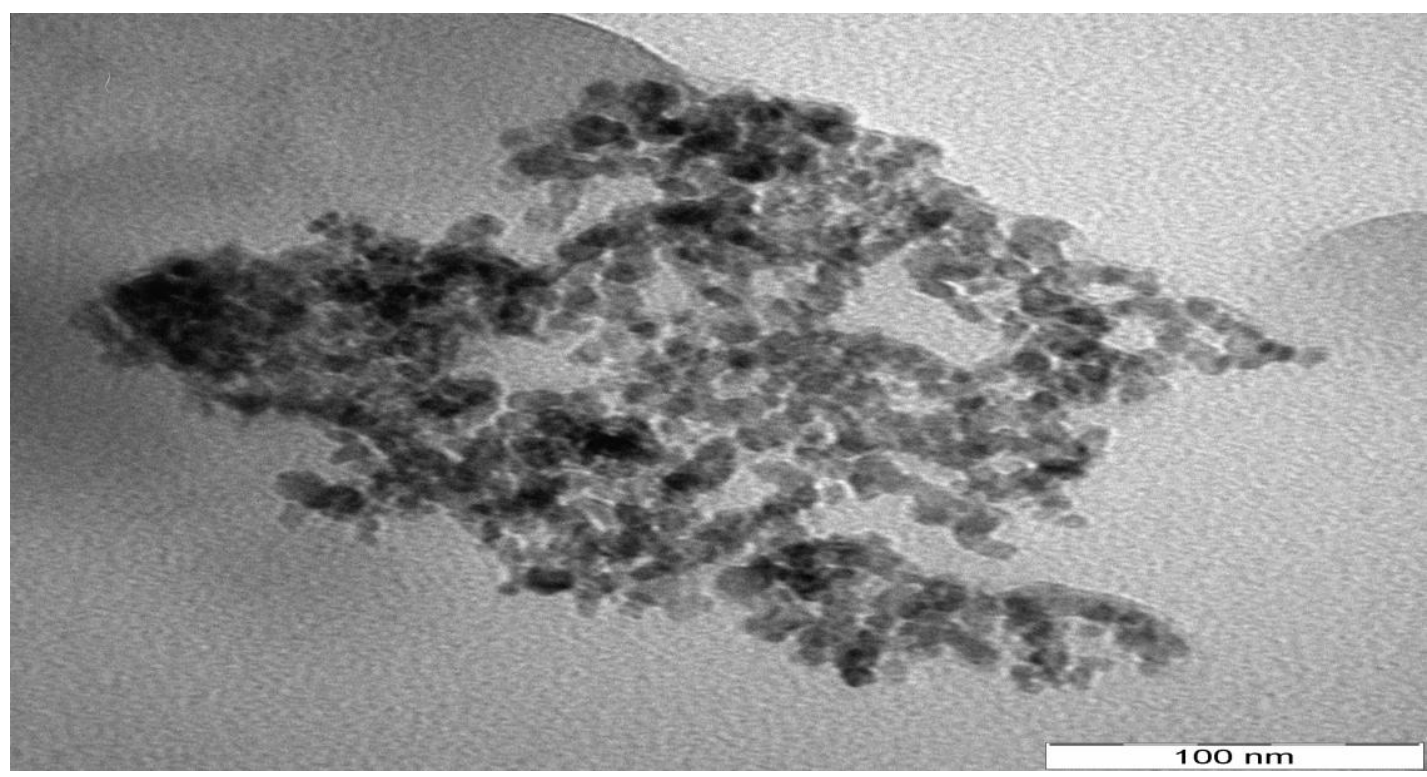

(c)

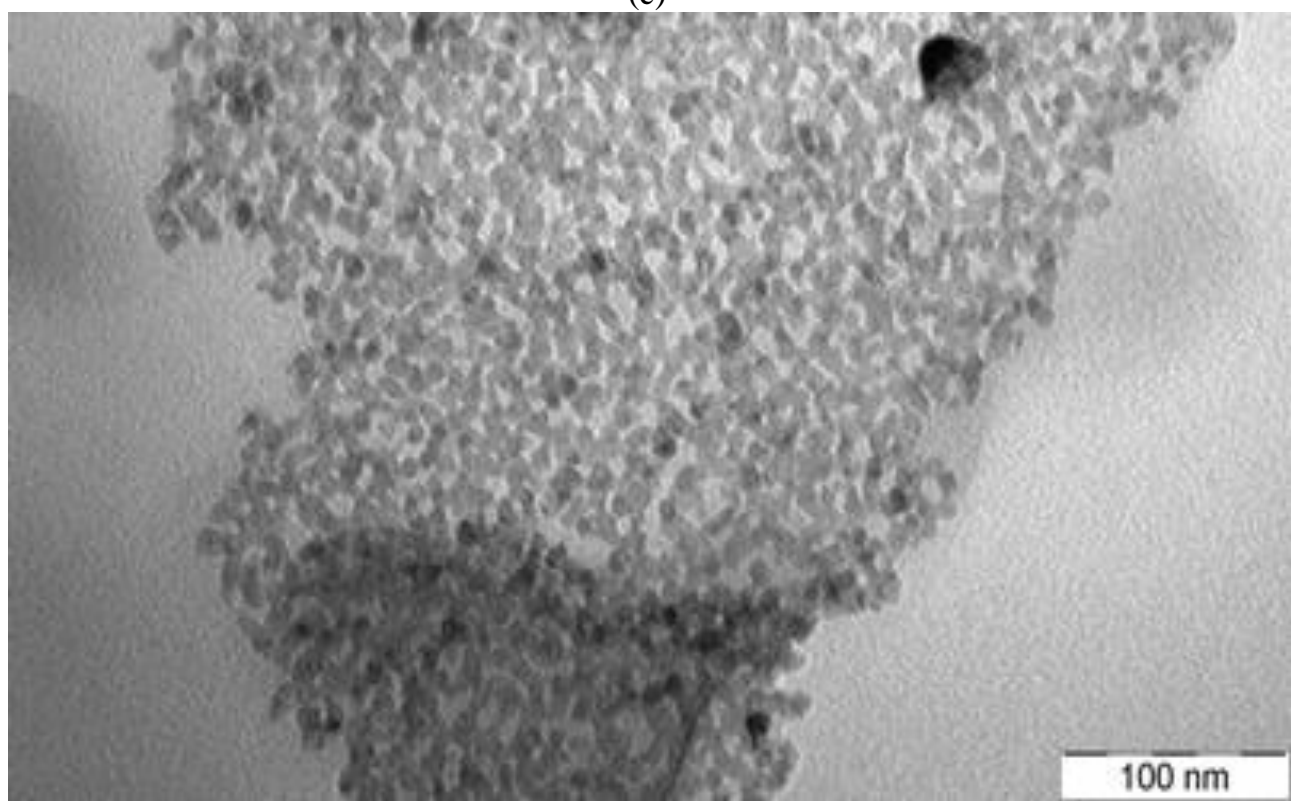

(d)

Fig. 5: TEM images of $\mathrm{Ni}_{0.5} \mathrm{Zn}_{0.5} \mathrm{Fe}_{2} \mathrm{O}_{4}$ nanoparticles calcined at (a) 723, (b) 773, (c) 823 and (d) $873 \mathrm{~K}$. 


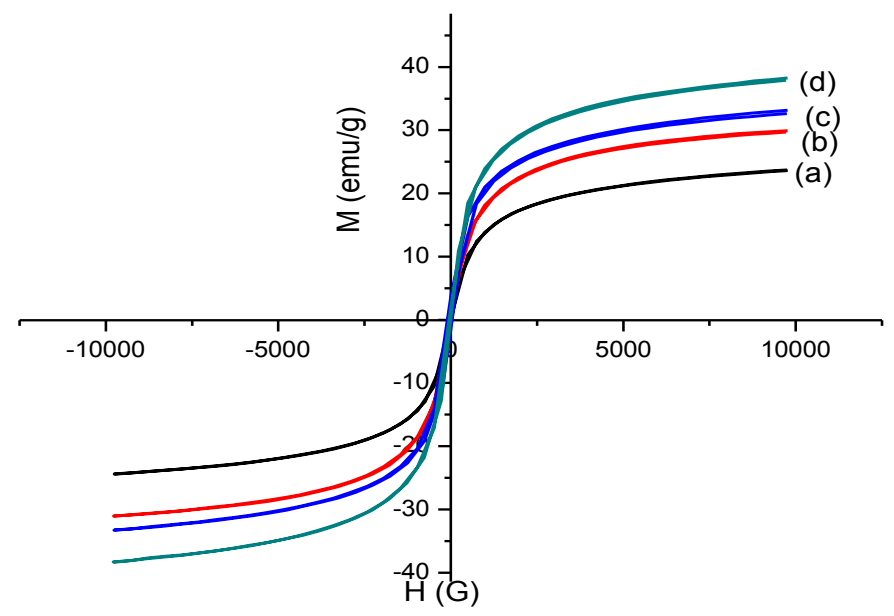

Fig. 6: VSM curves of $\mathrm{Ni}_{0.5} \mathrm{Zn}_{0.5} \mathrm{Fe}_{2} \mathrm{O}_{4}$ nanoparticles calcined at (a) 723, (b) 773, (c) 823 and (d) $873 \mathrm{~K}$.

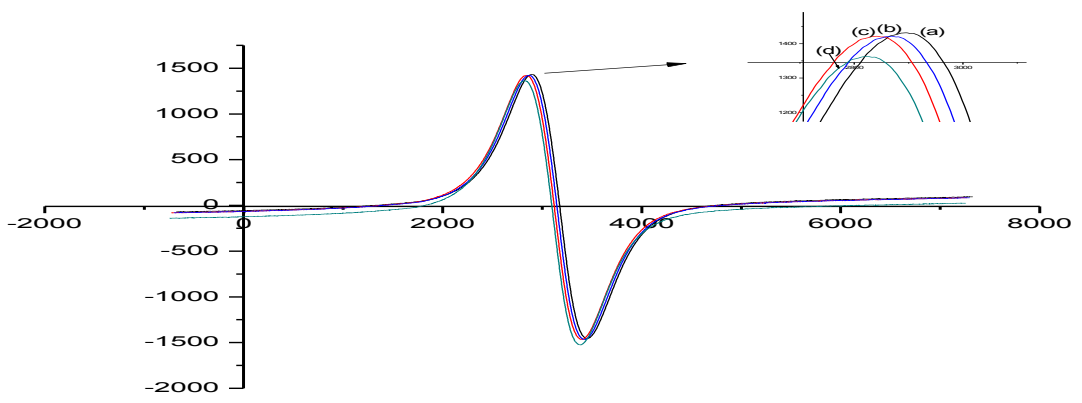

Figure 7: EPR spectra of $\mathrm{Ni}_{0.5} \mathrm{Zn}_{0.5} \mathrm{Fe}_{2} \mathrm{O}_{4}$ nanoparticles calcined at (a) 723, (b) 773, (c) 823 and (d) $873 \mathrm{~K}$. 